\title{
Peculiarities of Deposition Times on Gas Sensing Behaviour of Vanadium Oxide Thin Films
}

\author{
A. BAGHeri KhatibAni ${ }^{a, *}$, M. ABBASI ${ }^{b}$ And S.M. RozATI ${ }^{b}$ \\ ${ }^{a}$ Nano Research Lab, Lahijan Branch, Islamic Azad University, P.O. Box 1616, Lahijan, Iran \\ ${ }^{b}$ Physics Department, Faculty of Science, University of Guilan, Rasht 41335, Iran
}

(Received September 19, 2015; in final form April 12, 2016)

\begin{abstract}
The importance of vanadium oxide in solid state science as a semiconductor encouraged us to prepare and investigate its microstructure and surface properties related to gas sensing characteristics. Hence, vanadium oxide thin films were deposited by spray pyrolysis method. The prepared films were placed in an electric circuit and the sensing characteristics of these films to ethanol vapors were studied. It was possible to find correlations between nanostructure and electrical properties of the obtained thin films and to optimize conditions of its synthesis. By X-ray diffraction, field emission scanning electron microscopy, and atomic force microscopy, the structure of the deposited films was determined. Based on atomic force microscopy results, the fractal analysis showed a decreasing trend of the fractal dimension (the slope of the log (perimeter) vs. log (area)) versus the deposition time. It was found that the film growth and gas response were affected by the deposition time. The operating temperature of the sensor was optimized for the best gas response. In accordance with our findings, the film deposited at the lowest deposition time (20 min) had the highest sensing response to ethanol.
\end{abstract}

DOI: 10.12693/APhysPolA.129.1245

PACS/topics: 81.05.-t, 81.07.-b, 73.61.Le, 81.15.Rs

\section{Introduction}

Nanocrystalline metal oxides are very famous in gas sensors applications and they have attracted much attention due to their high sensitivity, fast response, and low operation temperature $[1,2]$. Transition metal oxides can sense gases by changing their electric conductance reversibly when the composition of the surrounding atmosphere is altered. It is known that the gas sensing behavior of metal oxide gas sensor is related to the microstructure of thin films [3]. It is the surface of the sensing element that interacts with the surrounding gaseous atmosphere. The high porosity and resultant surface roughness of the nanostructures result in a larger surface area rendering them very attractive to be used as efficient gas sensors [4]. Thus to find new gas sensing materials, one can try to utilize solids known for their catalytic properties, such as vanadium oxide. Conventional ethanol sensors mostly based on $\mathrm{SnO}_{2}, \mathrm{ZnO}, \mathrm{TiO}_{2}$ and $\mathrm{Fe}_{2} \mathrm{O}_{3}$, usually suffer from cross sensitivity to other gases, need a high working temperature, or have low longterm stability, although they have rather high sensitivity to ethanol vapour. For these, some new types of ethanol sensing materials are still being studied and developed. Vanadium oxide was found to possess highly selective and stable sensing properties to ethanol vapour [5].

Vanadium oxide is generally a non-stoichiometric material, which is known for its catalytic properties in oxidation reactions. The excellent properties such as multiple valences, wide optical band gap, good chemical and

*corresponding author; e-mail: bagherikhatibani@Liau.ac.ir thermal stability, excellent thermoelectric property, etc., make vanadium oxide a promising material for microelectronic, electrochemical, gas sensing, and optoelectronic devices [6, 7]. Vanadium oxide thin films have been prepared on different substrates by various methods such as electron beam evaporation [8], magnetron sputtering $[9,10]$, pulsed laser deposition [11, 12], chemical vapor deposition [13], spray pyrolysis [14, 15], solvothermal [16], sol-gel [17, 18], and spin coating [19].

Among numerous methods, spray pyrolysis has an important position since it is very simple, low cost method over large area [20], and does not require vacuum or exotic gas. In this method, the deposition process needs fine droplets to react on the heated substrate, owing to the pyrolytic decomposition of the solution. The hot substrate provides the thermal energy for the thermal decomposition and subsequent recombination of the constituent species. The phenomenon for the preparation of a metal oxide thin film depends on surface hydrolysis of metal salt on a heated substrate surface [21, 22]. Thus, the substrate temperature, carrier gas flow, substrate rotating speed, number of spraying sequences, spraying distance and duration, solution flow rate and molarity play an important role in forming the structure of the films ranging from amorphous to crystalline.

A highly selective and easy to use alcohol sensor has always been in great demand in biomedical, chemical, and food industries. Ethyl alcohol is the most important alcohol owing to its various applications such as an alternative to automotive fuels. Ethanol is widely used as well in food industry, brewing process control, medical and clinical applications, and bio-technological processes [23]. 
The purpose of this investigation is to determine influence of deposition time on the nanostructure properties of vanadium oxide thin films for enhanced ethanol sensing application. In this work, vanadium oxide films were deposited on glass substrates by spray pyrolysis method. We report the results of the sensing properties of vanadium oxide thin films. The deposition time was optimized to achieve the best sensing characteristics to ethanol.

\section{Experimental details}

Nanostructure vanadium oxide thin films were deposited on glass substrates by spraying $0.05 \mathrm{M}$ of $\mathrm{VCl}_{3}$ powder $\left(96 \%\right.$, purchased from Fluka) in $40 \mathrm{~cm}^{3}$ doubly distilled water. The pyrolysis temperature was fixed at $500{ }^{\circ} \mathrm{C}$ and the deposition time was varied between 20 and $60 \mathrm{~min}$. The gas flow rate was kept constant at $14 \mathrm{l} / \mathrm{min}$ and the distance of nozzle-substrate was about $25 \mathrm{~cm}$. The substrates were washed with water, rare nitric acid, acetone and they were cleaned in ultrasonic bath.

The as-deposited films were applied for the measurement of gas sensing properties. The gas sensing properties were evaluated at various operation temperatures from 150 to $350^{\circ} \mathrm{C}$ by measuring the changes of resistance of the sensor in air and in ethanol vapour, respectively.

In order to study the gas sensitivity of the prepared vanadium oxide thin films, glass chamber was fabricated (the volume of chamber was $650 \mathrm{~cm}^{3}$ ). Electrical connections were made with wire with very low resistance taken from the surface of the film using a silver paste. For the study of the ethanol response, a pre-determined amount of solvent was injected in the chamber. A small heater was placed on the bottom of the chamber and adjusted at a defined temperature. The sensing response was tested with a reducing gas (ethanol) at different concentrations. Simultaneously, the resistance variation of the sensing element was measured. During the measurement, the ambient relative humidity was about $59 \%$ and the room temperature was about $25^{\circ} \mathrm{C}$. The structural characterizations of the films were studied by X-ray diffraction (XRD) using a Philips PW 1800 powder diffractometer using Nifiltered $\mathrm{Cu} K_{\alpha}$ radiation $(0.15406 \mathrm{~nm})$. The morphology of thin films was observed by field emission scanning electron microscopy (FESEM) using a Hitachi S4160 (Hitachi Japan) electron microscope and atomic force microscopy (AFM) was also applied for morphological studies using a Veeco CP Research instrument.

\section{Results and discussion}

The structural properties of the prepared samples were studied by using XRD. The XRD pattern of the asprepared sample in Fig. 1 clearly shows that the crystalline phase of vanadium oxide is formed. Although different vanadium oxide phases are formed, but the orthorhombic $\mathrm{V}_{2} \mathrm{O}_{5}$ phase is visible (JCPDS No. 41-1426). It is evident that by varying the deposition time, various reflection planes are presented but the determined
(001) reflection plane is attended in all samples which is a characteristic peak of $\mathrm{V}_{2} \mathrm{O}_{5}$ phase.

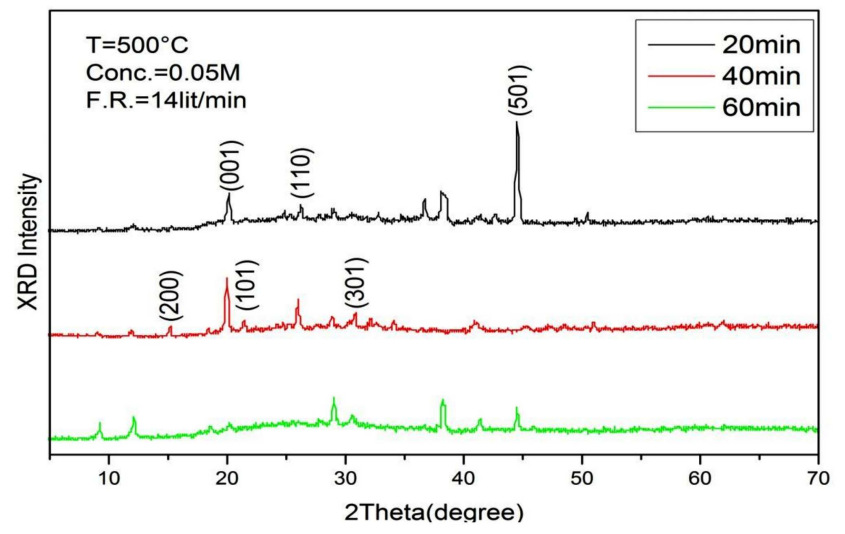

Fig. 1. X-ray diffraction pattern of vanadium oxide thin films.

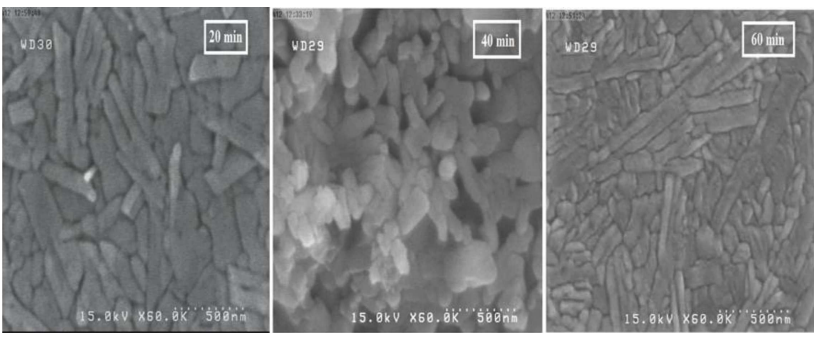

Fig. 2. The SEM images of vanadium oxide samples (from left to right $20 \mathrm{~min}, 40 \mathrm{~min}$, and $60 \mathrm{~min}$, respectively).

The surface morphologies of vanadium oxide films with different deposition times were characterized by scanning electron microscope (Fig. 2). The FESEM image of the film that is formed during $20 \mathrm{~min}$ shows that nanorods are placed horizontally on the surface and grain boundaries are visible. With increasing deposition time until $60 \mathrm{~min}$, it can be seen that the rods are strongly bonded together. Such elongated structure especially with distinct boundaries is valuable because of its microstructure features for gas-sensing application [24].

Microroughness of thin films plays a vital role for developing optical coatings. Surface roughness is the surface texture measurement of the film. The real surface geometry is so complicated that a finite number of parameters cannot provide a full description [25]. Parameters used to describe surface morphology are largely statistical indicators obtained from many samples of the surface height. Average roughness $\left(r_{\text {avg }}\right)$ is defined as the mean absolute values of the profile heights measured from a mean plane averaged over the sampling area, while the root mean square (RMS) roughness $\left(r_{\mathrm{RMS}}\right)$ is the standard deviation of the surface from the mean plane over the sampling area [26].

Surface morphology of the present films is shown in Fig. 3. The 3D and 2D AFM images are shown with the histograms of height distribution of the films. 

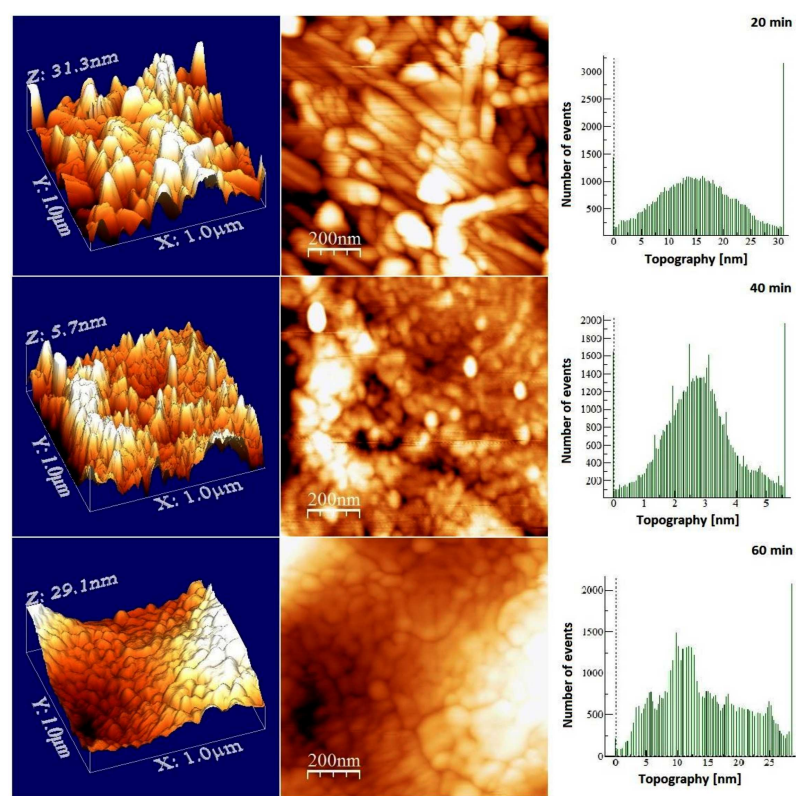

Fig. 3. The 3D and 2D AFM images along with the histograms of height distribution (from left to right) of vanadium oxide samples (from top to down $20 \mathrm{~min}$, $40 \mathrm{~min}$, and $60 \mathrm{~min}$, respectively).

The statistical analysis of AFM data was done using the height distribution. The results are listed in Table I. It is obvious that a rather decreasing trend is prevailed with the increase of deposition time and we are faced with more roughness about the first thin film which is favorable for gas sensing application because of its more trapping situation. A more normalized distribution along with appropriate roughness also belongs to the first sample which is our optimized film.

TABLE I

The root mean square, average roughness and fractal parameters of the samples.

\begin{tabular}{c|c|c|c|c}
\hline \hline Sample & $r_{\mathrm{RMS}}[\mathrm{nm}]$ & $r_{\mathrm{AVG}}[\mathrm{nm}]$ & $\alpha$ & $D$ \\
\hline (1) $20 \mathrm{~min}$ & $7.69 \pm 0.01$ & $6.22 \pm 0.01$ & $0.651 \pm 0.0005$ & $1.302 \pm 0.0005$ \\
(2) $40 \mathrm{~min}$ & $1.25 \pm 0.01$ & $0.96 \pm 0.01$ & $0.632 \pm 0.0005$ & $1.263 \pm 0.0005$ \\
(3) $60 \mathrm{~min}$ & $7.13 \pm 0.01$ & $5.96 \pm 0.01$ & $0.538 \pm 0.0005$ & $1.075 \pm 0.0005$
\end{tabular}

The fractal dimension is a particular parameter used to define the morphology of a surface. The surface morphology can be characterized qualitatively by its roughness and its fractal dimension. The idea of using the concepts of fractal geometry in the study of geometric figures and irregular shapes was popularized by Mandelbrot [27].

A fractal is defined by the property of self-similarity or self-affinity, i.e., they have the same characteristics for different variations in scale. To perform a fractal analysis, one needs to obtain information about the auto similarity of the shapes of different objects in an image.

The WSXM software provides a variety of histograms, such as the number of islands versus islands' area or the number of islands versus islands' perimeter. Using this

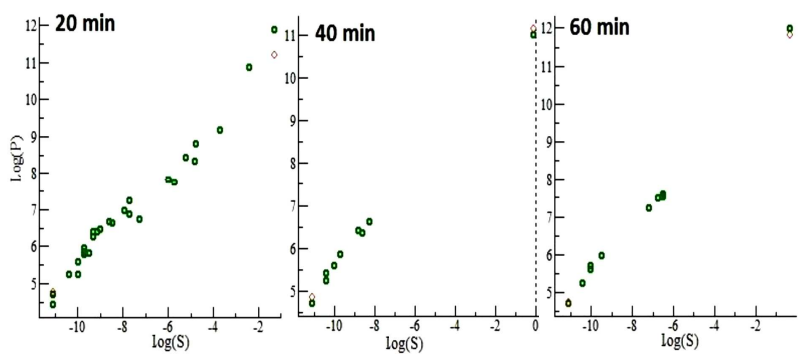

Fig. 4. The plot of fractal analysis for vanadium oxide thin films.

method the fractal dimension can also be calculated [28], the fractal analysis of the present samples has been performed (Fig. 4). The slope of the fit line of the log (perimeter) versus log (area) gives the power of the area related to the perimeter. Many fractal properties investigation methods exist [29-31]. Here, only one aspect needs to be mentioned: fractality is closely connected with selfsimilarity or scale-invariance. Fractal structures can be described as follows:

$$
P=\mu S^{\alpha}, \quad \alpha=\frac{D}{2},
$$

where $P$ is the perimeter, $\mu$ is a constant and $S$ is the area. The value of $\alpha$ describes the fractal dimension in our graph and $D$ (the parameter usually used for fractals) stands for the autosimilarity. The relevant values for $\alpha$ were $0.651,0.632$, and 0.538 , respectively. The decrease trend can be observed in the values of $\alpha$ and $D$ being the indicative of the reducing perimeter to the surface of the samples.

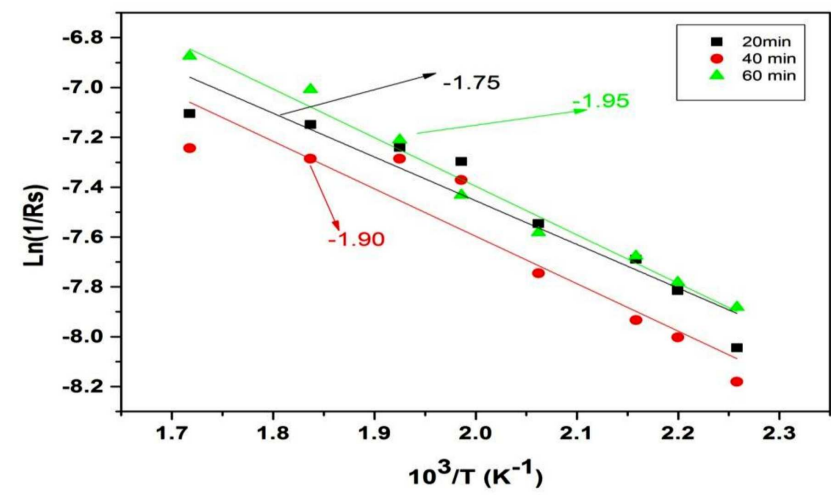

Fig. 5. Dependence of resistance on temperature for vanadium oxide films as a function of reciprocal temperature.

Figure 5 shows the change of resistance as a function of reciprocal temperature for vanadium oxide thin films in the range of $175-325^{\circ} \mathrm{C}$. The results indicate that the change of resistance with temperature has a typical Arrhenius behaviour. When the deposition time was increased, the electrical resistivity of the films increased. Generally, the resistivity of the film can be affected by isotropic background scattering due to external surface 
and grain boundaries [32]. The fitted line using the Arrhenius equation can be used to estimate the activation energy. The minimum amount of energy that must be provided to the reaction takes place, called the activation energy. The response of a semiconductor oxide gas sensor to the presence of a given gas depends on the speed of the chemical reaction on the surface of the grains and the speed of diffusion of the gas molecules to that surface which are activation processes, and the activation energy of the chemical reaction is higher. At low temperatures the sensor response is restricted by the speed of the chemical reaction, and at higher temperatures it is restricted by the speed of diffusion of gas molecules. At some intermediate temperature, the speed values of the two processes become equal, and at that point the sensor response reaches its maximum [33]. This temperature is also named as optimal operating temperature and will be calculated later. It is known that the smaller is the activation energy of chemisorption and the higher is the activation energy of desorption, the bigger is gassensing effect of adsorption type sensors [34].

The slope values of the samples are $-1.75,-1.90$, and -1.95 and their standard errors are $0.21,0.28$, and 0.11 , respectively. It is clear that the slope of the fitted line increases with increase of the deposition times. The activation energy of the relevant samples was calculated as $14.54,15.80$, and $16.12 \mathrm{~kJ} / \mathrm{mol}$, respectively. Our optimized film needs the least activation energy which is favoured.

The sensing response was determined by injecting of ethanol at different concentrations and measuring real-time changes in resistance over two electrodes. The changes in sensor resistance can be caused by different facts such as ion adsorption of gas molecules, surface reaction of target gas with adsorbed oxygen or lattice oxygen [35].

Different mechanisms are responsible for the response of vanadium oxide thin films to ethanol, but it seems one of the important ones is environmental oxygen contribution. Initially, oxygen is adsorbed on the metal oxide surface when the film is heated in air. At lower temperatures, the surface reactions proceed too slowly to be effective. The adsorption of oxygen forms ionic species including $\mathrm{O}_{2}^{-}, \mathrm{O}^{-}$, and $\mathrm{O}^{2-}$, which have acquired electrons from the conduction band. The transferring of the electrons from the conduction band to the chemisorbed oxygen results in the decrease of the electron concentration in the film. For $n$-type semiconducting metal oxides, an increase in the resistance of metal oxide film is observed [36]. When ethanol is present in the atmosphere it gets adsorbed and subsequently reacts with the sensing layer provided that the applicable thermodynamic conditions are favored. This reaction leads to the decrease of the atomic oxygen on the surface. Its conductivity increases through the adsorption and reaction of ethanol. This conductivity increase accompanied with a reduction in the measured resistance. On the other hand, for $n$-type semiconductor, the chemisorbed oxygen on the surface reacts with the reductive gas species and the electrons trapped by oxygen are released into the conduction band of the semiconductor, leading to resistance decrease [23].

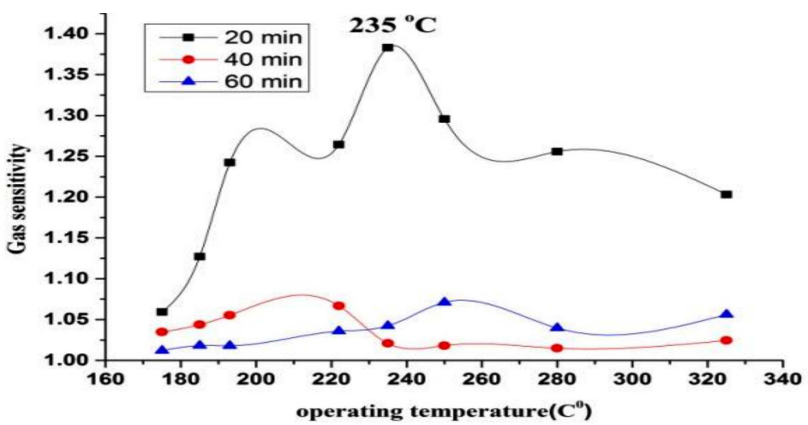

Fig. 6. Variation of the gas sensitivity of the samples as a function of temperature (ethanol concentration $2500 \mathrm{ppm}$ ).

The operating temperature dependence of the sensing properties could result from changing the adsorption and desorption rates of oxygen ions on the metal-oxide surface [37]. To determine the optimum operating temperature, sensitivity of vanadium oxide films to $2500 \mathrm{ppm}$ ethanol vapor was measured at different operating temperatures. The variation of temperature was in the range of $170-330^{\circ} \mathrm{C}$ and the sensitivity was investigated. The results are shown in Fig. 6. The response increases and reaches to its maximum value at $235^{\circ} \mathrm{C}$, then decreases rapidly at higher temperatures. This might be attributed to the competing desorption of the chemisorbed oxygen [38]. When the working temperature is higher than $235^{\circ} \mathrm{C}$, the chemical adsorption oxygen absorbed on the surface of the films will gain enough energy to desorb from the surface, and then the chemical adsorption oxygen get the saturation. With increase of operating temperature, the rate of desorption is much higher than that of adsorption, limited the reaction between adsorption oxygen and target gas molecules and further reduced response.

Such operating temperature is much less than the operating temperature of our $\mathrm{In}_{2} \mathrm{O}_{3}$ thin films [39]. Since most of metal oxides have the operating temperature of $300-450{ }^{\circ} \mathrm{C}$ [40], this relatively low working temperature is attractive for cheap device applications because of lower power consumption [23]. It is evident, if we reduce the operating temperature by technological methods down to room temperature, we can remove the heater part (for increasing temperature), chamber space, portability and other relevant requirements.

The sensors were tested on exposure of 500-2500 ppm concentration of ethanol at an operating temperature of $235^{\circ} \mathrm{C}$. The heater is controlled by altering the voltage $\left(V_{\mathrm{H}}, \mathrm{dc}\right)$. To measure the electrical signal of the sensing film, a voltage of $4 \mathrm{~V}$ was applied to the signal electrode $\left(V_{\mathrm{in}}, \mathrm{ac}\right)$. The response of the gas sensor is defined as [36]: 


$$
s=\frac{R_{\mathrm{a}}(\Omega)}{R_{\mathrm{g}}(\Omega)}=\frac{\frac{V_{\mathrm{in}}(\mathrm{V})}{V_{\mathrm{a}}(\mathrm{V})}-1}{\frac{V_{\mathrm{in}}(\mathrm{V})}{V_{\mathrm{g}}(\mathrm{V})}-1},
$$

where $R_{\mathrm{a}}$ is the baseline resistance of the sensing film in pure air and $R_{\mathrm{g}}$ is the resistance in a gas environment. $V_{\text {in }}$ is source voltage in air and $V_{\mathrm{g}}$ is variant resistor voltage. The sensing responses as a function of the vapor concentration from $500 \mathrm{ppm}$ to $2500 \mathrm{ppm}$ are shown in Fig. 7.

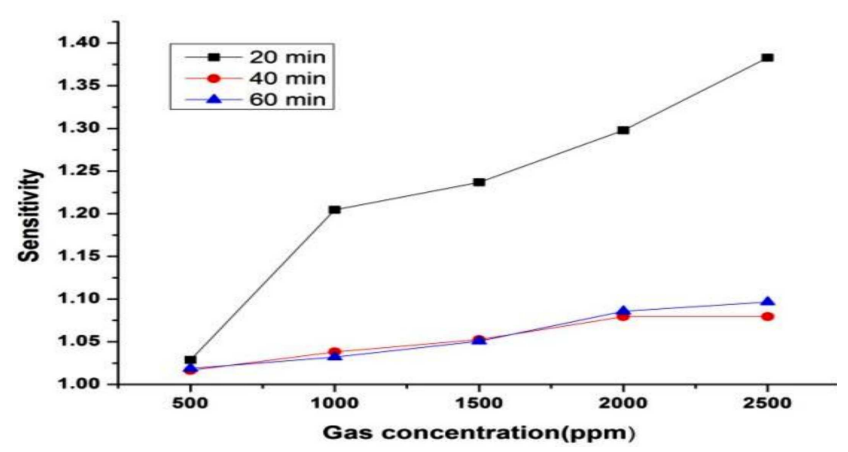

Fig. 7. The sensing response vanadium oxide thin films as a function of gas concentration.

The sensitivity increased linearly with different ethanol concentrations. It was found that films deposited at the lowest deposition time (20 min) had the highest sensing response to ethanol. This result confirmed the role of surface and microstructure effect for gas sensing application because the first sample has been covered by horizontal elongated rods with distinct boundaries which increases porosity. According to the literature, the porous structure of sensing material can bring inveterate enhancement in the gas sensing properties [41], since it provides a large active area to interact with the gas, and allow the gas to diffuse agilely [23]. The first sample also had the highest roughness which can facilitate trapping of gas species. In addition to the surface and microstructure of the films, it is good to have a look at the amount of thickness; the thicknesses of the vanadium oxide films were 640,830 , and $998 \mathrm{~nm}$, respectively. A straightforward conclusion is the reverse role of thickness on gas sensing properties of the films. It may be better to use thinner films to improve sensing characteristics [3, 42].

The real-time sensor responses to ethanol are displayed in Fig. 8. When the reducing gas is exposed to the sensing element the voltage increases, which confirms the typical characteristic of an $n$-type semiconductor [14]. It can be seen that the sensing response increases instantly upon the introduction of ethanol, but it decreases rapidly and eventually returns to its initial value. The response magnitude of the vanadium oxide increases with higher ethanol concentration. The response of the sample with the lowest deposition time is much higher than that of the film with higher deposition time. After several cycles between the ethanol vapor and fresh air, the voltage of the sensor returns to its initial state indicating that the sensor has a good reversibility. It is well known that both

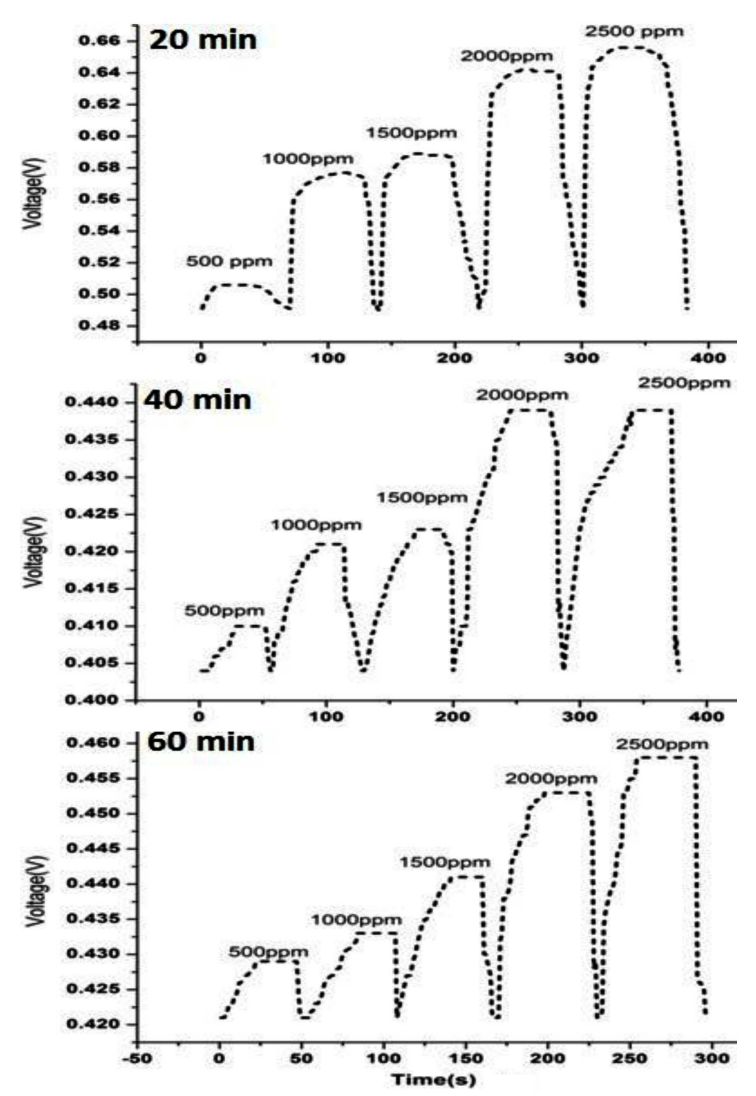

Fig. 8. Dynamic response characteristics of vanadium oxide thin films exposed to ethanol concentration of $500-2500 \mathrm{ppm}$ at $235^{\circ} \mathrm{C}$.

the response and the recovery characteristics are important for evaluating the performance of gas sensors. When the selected sample was exposed to $1000 \mathrm{ppm} \mathrm{C}_{2} \mathrm{H}_{5} \mathrm{OH}$, the response and recovery times were 2.43 and $15.71 \mathrm{~s}$, respectively. The response time is defined as the time required for the sample conductance variation to reach $90 \%$ of the equilibrium value following an injection of the test gas. The recovery time is defined as the time necessary for the sample to return to $10 \%$ above the original conductance in air after the test gas has been released.

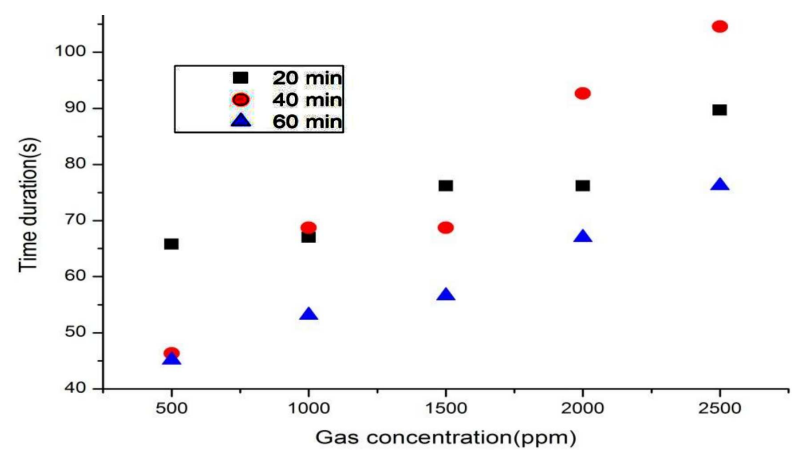

Fig. 9. Time duration of vanadium oxide thin films versus various gas concentrations. 
Figure 9 shows the change of time duration of vanadium oxide thin films versus different gas concentrations. This is the time between injection of the gas, reaching saturation and exhaust of the gas. From this point of view our third sample which has most of the deposition time has the lowest saturation time though it has not an appropriate sensitivity in comparison with our selected sample.

TABLE II

Comparison between conventional ethanol vapor sensor and our vanadium oxide sensor.

\begin{tabular}{|c|c|c|c|c|c|}
\hline $\begin{array}{l}\text { Sensing } \\
\text { material }\end{array}$ & Sensitivity & $\begin{array}{c}\text { Response/recovery } \\
\text { time }[\mathrm{s}]\end{array}$ & $\begin{array}{c}\text { Optimal operating } \\
\text { temperature }\left[{ }^{\circ} \mathrm{C}\right]\end{array}$ & $\begin{array}{c}\text { Maximum testing } \\
\text { temperature }\left[{ }^{\circ} \mathrm{C}\right] \\
\text { (thermal stability) }\end{array}$ & References \\
\hline $\mathrm{WO}_{3}$ hollow spheres & $7.79(1000 \mathrm{ppm})$ & $-/-$ & 300 & 450 & {$[43]$} \\
\hline $\mathrm{ZnO}$ nanosheets & 40 (100 ppm) & $-/-$ & 400 & 425 & [44] \\
\hline ZnO long nanofibers & $51(100 \mathrm{ppm})$ & $7-9 / 9-11$ & 270 & 450 & [45] \\
\hline $\mathrm{ZnO}$ nanowires & $5.3(500 \mathrm{ppm})$ & $25 / 25$ & 300 & 300 & {$[46]$} \\
\hline $\mathrm{ZnO}$ nanorods arrays & 39 (1000 ppm) & $5 / 7$ & 340 & 460 & {$[47]$} \\
\hline $\mathrm{ZnO}$ nanorods & 41 (1000 ppm) & $10 / 20$ & 350 & 440 & [38] \\
\hline $\mathrm{In}_{2} \mathrm{O}_{3}$ & 34 (1000 ppm) & $20 / 35$ & 35 & 35 & [48] \\
\hline $\mathrm{In}_{2} \mathrm{O}_{3}$ nanofibers & $14(100$ ppm $)$ & $1 / 5$ & 300 & 340 & [49] \\
\hline $\mathrm{In}_{2} \mathrm{O}_{3}$ hollow microspheres & $137.2(100 \mathrm{ppm})$ & $2 / 830$ & 400 & - & {$[50]$} \\
\hline $\mathrm{Fe}_{2} \mathrm{TiO}_{5}$ hollow spheres & $175.1(1000 \mathrm{ppm})$ & $-/-$ & 320 & 420 & [51] \\
\hline $\mathrm{ZnFe}_{2} \mathrm{O}_{4}$ thin film & $3.66(50 \mathrm{ppm})$ & $40 / 120$ & 390 & 400 & [52] \\
\hline $\mathrm{Nb} / \mathrm{TiO}_{2}$ & $17(400$ ppm $)$ & $3 / 79$ & 500 & 550 & [53] \\
\hline $\mathrm{V}_{2} \mathrm{O}_{5}$ nanobelts & - & $50 / 50$ & 200 & 400 & {$[5]$} \\
\hline $\mathrm{V}_{2} \mathrm{O}_{5}$ nanorods & $1.02(1000 \mathrm{ppm})$ & $-/-$ & room temperature & room temperature & [16] \\
\hline $\mathrm{V}_{2} \mathrm{O}_{5}$ flower-like network & $11(1000 \mathrm{ppm})$ & $30 / 30$ & 250 & 300 & [23] \\
\hline vanadium oxide & $1.2(1000 \mathrm{ppm})$ & $2.43 / 15.71$ & 235 & 330 & this work \\
\hline
\end{tabular}

Since, on the one hand the most important aspect of investigation of a variety of sensors is sensitivity, selectivity and stability, and on the other hand conventional ethanol sensors mostly based on $\mathrm{ZnO}, \mathrm{TiO}_{2}, \mathrm{SnO}_{2}$ and $\mathrm{Fe}_{2} \mathrm{O}_{3}$; we compared our sensor with such materials in similar conditions. Although finding a sensor material which has very high sensitivity, very fast response and recovery time, long-term stability and works under environmental condition is highly desirable, but very difficult. The results are given in Table II. It is notable that lowering of operation temperature and response time can be rather advantage of our sensor material. We did not examine other gases but there are some reports of vanadium oxide sensors which exhibit more sensitivity toward ethanol against other gases that means that such material has a good selectivity [16].

\section{Conclusions}

Nanocrystalline vanadium oxide thin films have been deposited by a simple spray pyrolysis method at different deposition times. A prevailed $\mathrm{V}_{2} \mathrm{O}_{5}$ structure was revealed by XRD analysis according to standard diffraction peaks. It was found by FESEM that the deposition time plays a key role in the morphology of the films. AFM results showed a rather decrease trend with increasing deposition time (the root mean square varied between
7.69 and $1.2 \mathrm{~nm}$ and average roughness changed between 6.22 and $0.96 \mathrm{~nm}$ ). The subsequent fractal measurements also revealed a decrease form in accordance with AFM data. The activation energy of the vanadium oxide thin films were estimated similar to the Arrhenius formulation and were $14.54,15.80$, and $16.12 \mathrm{~kJ} / \mathrm{mol}$, respectively. After the optimization of the operating temperature, $235^{\circ} \mathrm{C}$ were chosen. The sensing characteristics of the films have been characterized for different deposition times at different ppm levels (500-2500 ppm). The sensitivity response changed linearly with ethanol. The results show that the sensitivity of sample 1 (20 min) varied between 1.02 and 1.4, whereas two other samples had poorer sensitivity responses (1.02 and 1.12) in the same ppm range so it seems that the short duration of deposition has been positive parameter for sensing response. A valuable interaction to ethanol with a response time of $2.43 \mathrm{~s}$ and recovery time of $15.71 \mathrm{~s}$ was achieved by our optimized sample at a gas concentration of 1000 ppm.

\section{References}

[1] M. Stamataki, D. Tsamakis, N. Brilis, I. Fasaki, A. Giannoudakos, M. Kompitsas, Phys. Status Solidi A 205, 2064 (2008).

[2] A. Bagheri Khatibani, A. Abdolahzadeh Ziabari, S.M. Rozati, Z. Bargbidi, G. Kiriakidis, Trans. Electr. Electron. Mater. 13, 111 (2012). 
[3] A.M. Soleimanpour, Y. Hou, A.H. Jayatissa, Sens. Actuat. B 182, 125 (2013).

[4] A. Dhayal Raj, P. Suresh Kumar, Q. Yang, D. Mangalaraj, Physica E 44, 1490 (2012).

[5] J. Liu, X. Wang, Q. Peng, Y. Li, Adv. Mater. 17, 764 (2005).

[6] C.V. Ramana, N.B. Srinivasalu, C. Julien, M. Balkanski, Mater. Sci. Eng. B 52, 32 (1998).

[7] B.H. Kim, A. Kim, S.Y. Oh, S.S. Bae, Y.J. Yun, H.Y. Yu, Appl. Phys. Lett. 93, 233101 (2008).

[8] C.V. Ramana, O.M. Hussain, B. Srinivasulu Naidu, P.J. Reddy, Vacuum 48, 431 (1997).

[9] H.N. Cui, V. Teixeira, L.J. Meng, R. Wang, J.Y. Gao, E. Fortunato, Thin Solid Films 516, 1484 (2008).

[10] Zh. Luo, Zh. Wu, X. Xu, M. Du, T. Wang, Y. Jiang, Vacuum 85, 145 (2010).

[11] J. Huotari, R. Bjorklund, J. Lappalainen, A. Lloyd Spetz, Sens. Actuat. B 217, 22 (2015).

[12] C.V. Ramana, R.J. Smith, O.M. Hussain, C.C. Chusuei, C.M. Julien, Chem. Mater. 17, 1213 (2005).

[13] M.B. Sahana, S.A. Shivashankar, J. Mater. Res. 19, 2859 (2004)

[14] A.A. Akl, J. Phys. Chem. Solids 71, 223 (2010).

[15] A. Bouzidi, N. Benramdane, A. Nakrela, C. Mathieu, B. Khelifa, R. Desfeux, A. Da Costa, Mater. Sci. Eng. B 95, 141 (2002).

[16] A. Dhayal Raj, T. Pazhanivel, P. Suresh Kumar, D. Mangalaraj, D. Nataraj, N. Ponpandian, Curr. Appl. Phys. 10, 531 (2010).

[17] M. Benmouss, A. Outzourhit, R. Jourdani, A. Bennouna, E.L. Ameziane, Act. Pass. Electron. Comp. 26, 245 (2003).

[18] J. Livage, G. Guzman, F. Beteille, P. Davidson, J. Sol-Gel Sci. Technol. 8, 857 (1997).

[19] M.B. Sahana, C. Sudakar, C. Thapa, G. Lawes, V.M. Naik, R.J. Baird, G.W. Auner, R. Naik, K.R. Padmanabhan, Mater. Sci. Eng. B 143, 42 (2007).

[20] A. Bagheri Khatibani, Z.A. Hallaj, S.M. Rozati, Eur. Phys. J. Plus 130, 1 (2015).

[21] A. Bagheri Khatibani, S.M. Rozati, Bull. Mater. Sci. 38, 319 (2015).

[22] A. Bagheri Khatibani, S.M. Rozati, Bull. Mater. Sci. 39, 97 (2016).

[23] V.S. Vaishnav, P.D. Patel, N.G. Patel, Thin Solid Films 490, 94 (2005).

[24] Y. Qin, G. Fan, K. Liu, M. Hu, Sens. Actuat B 190 141 (2014).

[25] A. Bagheri Khatibani, S.M. Rozati, J. Non-Cryst. Solids 363, 121 (2013).

[26] M. Pelliccione, T.M. Lu, Evolution of Thin Film Morphology: Modeling and Simulations, Springer, Berlin 2008

[27] R.R.L. De Oliveira, D.A.C. Albuquerque, T.G.S. Cruz, F.M. Yamaji, F.L. Leite, in: Atomic Force Microscopy - Imaging, Measuring and Manipulating Surfaces at the Atomic Scale, Ed. V. Bellitto, InTech, 2012, Ch. 7.
[28] J.S.Y. Wang, B.L. Cox, Fractals 1, 547 (1993).

[29] A. Imre, T. Pajkossy, L. Nyikos, Acta Metall. Mater. 40, 1819 (1992).

[30] T. Pajkossy, J. Electroanal. Chem. Interf. Electrochem. 300, 1 (1991)

[31] M.A. Issa, M.A. Issa, M.S. Islam, A. Chudnovsky, Eng. Fract. Mech. 70, 125 (2003).

[32] A.F. Mayadas, M. Shatzkes, Phys. Rev. B 1, 1382 (1970).

[33] V.R. Shinde, T.P. Gujar, C.D. Lokhande, Sens. Actuat. B 120, 551 (2007).

[34] G. Korotcenkov, Mater. Sci. Eng. B Solid 139, 1 (2007).

[35] D. Kohl, Sens. Actuat. 18, 71 (1989).

[36] K. Wetchakun, T. Samerjai, N. Tamaekong, C. Liewhiran, C. Siriwong, V. Kruefu, A. Wisitsoraat, A. Tuantranont, S. Phanichphant, Sens. Actuat. B 160, 580 (2011).

[37] A.Z. Sadek, S. Choopun, W. Wlodarski, S.J. Ippolito, K. Kalantar-zadeh, IEEE Sens. J. 7, 919 (2007).

[38] L.J. Bie, X.N. Yan, J. Yin, Y.Q. Duan, Z.H. Yuan, Sens. Actuat. B 126, 604 (2007).

[39] M. Abbasi, S.M. Rozati, J. Electron. Mater. 45 , 2855 (2016)

[40] Ch. Wang, L. Yin, L. Zhang, D. Xiang, R. Gao, Sensors 10, 2088 (2010).

[41] N. Zhang, R. Yi, R. Shi, G. Gao, G. Chen, X. Liu, Mater. Lett. 63, 496 (2009).

[42] G. Korotcenkov, V. Brinzari, A. Cerneavschi, M. Ivanov, V. Golovanov, A. Cornet, J. Morante, A. Cabot, J. Arbiol, Thin Solid Films 460, 315 (2004).

[43] X.L. Li, T.J. Lou, X.M. Sun, Y.D. Li, Inorg. Chem. 43, 5442 (2004).

[44] D. Ju, H. Xu, J. Zhang, J. Guo, B. Cao, Sens. Actuat. B 201, 444 (2014).

[45] S. Wei, Sh. Wang, Y. Zhang, M. Zhou, Sens. Actuat. B 192, 480 (2014).

[46] N.V. Hieu, N.D. Chien, Physica B 403, 50 (2008).

[47] S. Ma, R. Li, C. Lv, W. Xu, X. Gou, J. Hazard. Mater. 192, 730 (2011).

[48] A. Kaur Bal, A. Singh, R.K. Bedi, Physica B 405 3124 (2010).

[49] W. Zheng, X. Lu, W. Wang, Zh. Li, H. Zhang, Yu Wang, Zh. Wang, C. Wang, Sens. Actuat. B 142, 61 (2009).

[50] S.J. Kim, I.S. Hwang, J.K. Choi, Y. Chan Kang, J.H. Lee, Sens. Actuat. B 155, 512 (2011).

[51] R. Yu, Z. Li, D. Wang, X. Lai, C. Xing, M. Yang, X. Xing, Scr. Mater. 63, 155 (2010).

[52] A. Sutka, J. Zavickis, G. Mezinskis, D. Jakovlevs, J. Barloti, Sens. Actuat. B 176, 330 (2010).

[53] S. Sujatha, K. Harjeet, V.N. Singh, K. Jain, T.D. Senguttuvan, Sens. Actuat. B 171-172, 899 (2012). 